\title{
Chemical Constituents from Terminalia glabrescens
}

\section{Fernanda R. Garcez*, Walmir S. Garcez, Daniel L. S. Miguel, Alessandro A. T. Serea and Fabiana C. Prado}

\author{
Departamento de Química, Centro de Ciências Exatas e Tecnologia, Universidade Federal de Mato Grosso do Sul, \\ 79070-900 Campo Grande - MS, Brazil
}

\begin{abstract}
Das folhas de Terminalia glabrescens foram obtidos um novo triterpeno pentacíclico $(3 \beta, 6 \beta, 23,28$ tetraidroxiolean-12-eno), além dos ácidos ursólico, $2 \alpha$-hidroxiursólico, oleanólico, maslínico, arjunólico, sumaresinólico e asiático, esqualeno, fitol, sitosterol-3-O- $\beta$-D-glucopiranosídeo e $n$ alcanos. Da casca do caule foram obtidos friedelina, taraxerol, lupeol, lupenona, betulina, betulona, ácido betulínico, arjunglucosídeo I, estigmastano-3 $\beta, 6 \alpha$-diol, $\beta$-sitosterol, (-) catequina, $\beta$-Dpiranotagatose, $\beta$-D-furanofrutose e $\alpha$-D-furanofrutose.
\end{abstract}

A new oleanane-type triterpene ( $3 \beta, 6 \beta, 23,28$-tetrahydroxyolean-12-ene) was isolated from the leaves of Terminalia glabrescens, together with ursolic, $2 \alpha$-hydroxyursolic, oleanolic, maslinic, arjunolic, sumaresinolic and asiatic acids, squalene, phytol, sitosterol-3-O- $\beta$-D-glucopyranoside and $n$-alkanes. Friedelin, taraxerol, lupeol, lupenone, betulin, betulone, betulinic acid, arjunglucoside I, stigmastane- $3 \beta, 6 \alpha$-diol, $\beta$-sitosterol, (-) catechin, $\beta$-D-pyranotagatose, $\beta$-D-furanofructose and $\alpha$ D-furanofructose were obtained from the trunk bark.

Keywords: Terminalia glabrescens, Combretaceae, triterpenes, 3 $\beta, 6 \beta, 23,28$-tetrahydroxyolean12-ene, stigmastane- $3 \beta, 6 \alpha$-diol

\section{Introduction}

Plants of the genus Terminalia (Combretaceae) are known as a rich source of secondary metabolites, such as pentacyclic triterpenes and their glycoside derivatives, flavonoids, tannins and other aromatic compounds, some of which with antibacterial, antifungal, anticancer and hepatoprotective activities. ${ }^{1-8}$

Terminalia glabrescens Mart., which has not previously been chemically investigated, is a medium-sized tree widespread in Mato Grosso do Sul, Brazil. In the present paper, we describe the isolation and structural elucidation of a new oleanane-type triterpene $(3 \beta, 6 \beta, 23,28$-tetrahydroxyolean-12-ene) from the leaves of this species. The known pentacyclic triterpenes ursolic, $2 \alpha$-hydroxyursolic, oleanolic, maslinic, arjunolic, sumaresinolic and asiatic acids together with squalene, phytol, sitosterol-3-O- $\beta$-Dglucopyranoside and foliar wax hydrocarbons were also obtained from the leaves, while the trunk bark afforded the triterpenes friedelin, taraxerol, lupeol, lupenone, betulin, betulone, betulinic acid and arjunglucoside I in

* e-mail: frgarcez@nin.ufms.br addition to stigmastane- $3 \beta, 6 \alpha$-diol, $\beta$-sitosterol, (-) catechin, $\beta$-D-pyranotagatose, $\beta$-D-furanofructose and $\alpha$ D-furanofructose.

The structures of the known and new compounds were established on the basis of spectral data, mainly ${ }^{1} \mathrm{H}$ and ${ }^{13} \mathrm{C}$ (1D and 2D) NMR spectra and by comparison with authentic samples.

\section{Results and Discussion}

The hexane and $\mathrm{CHCl}_{3}$ solubles obtained from partition of the ethanol extract of leaves were subjected to a series of normal and reversed phase silica gel column chromatography, gel filtration and preparative TLC on silica gel separations to yield the new pentacyclic triterpene $3 \beta, 6 \beta, 23,28$-tetrahydroxyolean-12-ene (1) in addition to ursolic, ${ }^{9}$ oleanolic, ${ }^{9} 2 \alpha$-hydroxyursolic, ${ }^{9}$ maslinic, ${ }^{9}$ sumaresinolic (2), ${ }^{9}$ asiatic (3) ${ }^{9}$ and arjunolic (4) ${ }^{9}$ acids, squalene, ${ }^{10}$ phytol, sitosterol-3-O- $\beta$-D-glucopyranoside and long chain hydrocarbons. These were characterized as $n$-alkanes in the range between $\mathrm{C}_{18}$ and $\mathrm{C}_{33}$, with a large predominance of chains with odd numbers of carbon atoms, where $\mathrm{C}_{29}$ and $\mathrm{C}_{31}$ were found as the main homologues. The isolation of squalene and of the triterpene $\mathbf{2}$ in the 
genus Terminalia is being reported for the first time. The known compounds were identified by their ${ }^{1} \mathrm{H}$ and ${ }^{13} \mathrm{C}$ NMR spectral data, by comparison with literature values and/or with authentic samples. Identification of $\mathbf{2}$ as well as the isomeric triterpenes maslinic / $2 \alpha$-hydroxyursolic acids and $\mathbf{3}$ / $\mathbf{4}$ was supported by conversion into their corresponding C-28 methyl ester derivatives whose ${ }^{1} \mathrm{H}$ and ${ }^{13} \mathrm{C}$ NMR resonances were in accordance with reported data. ${ }^{911}$ The alkane composition was determined on the basis of GC-FID retention times and by comparison with authentic standards.

Compound 1 was obtained as an amorphous solid and its HBBD ${ }^{13} \mathrm{C}$ NMR spectrum displayed signals for 30 carbon atoms. With the aid of information afforded by the DEPT spectra these signals could be attributed to seven quaternary, six methine, eleven methylene and six methyl carbon atoms. The presence of a trisubstituted double bond was inferred by the signals of a methine carbon at $\delta 123.0$ and a quaternary carbon at $\delta$ 144.4. In the HMQC spectrum a cross-peak correlation was observed between the former carbon signal and the broad hydrogen singlet at $\delta$ 5.57 , which was assigned to the vinylic hydrogen. In the ${ }^{1} \mathrm{H}$ NMR spectrum, the signals at $\delta 5.04$ (br s) and 4.26 (dd, $J 11.4$ and $4.1 \mathrm{~Hz}$ ) which showed connectivities in the HMQC spectrum with the carbon signals at $\delta 67.7$ and 73.4, respectively, were attributed to two carbinolic hydrogens. Similarly, the broad singlet at $\delta_{\mathrm{H}} 4.06(2 \mathrm{H})$ and the two doublets at $\delta_{\mathrm{H}} 4.38(1 \mathrm{H}, J 10.5 \mathrm{~Hz})$ and $4.03(1 \mathrm{H}, J$ $10.5 \mathrm{~Hz}$ ), which showed cross-peak correlations with the carbon signals at $\delta 64.5$ and 67.2, respectively, were assigned to hydroxymethylene hydrogens. These information, along with the absorption at $v_{\max } 3429 \mathrm{~cm}^{-1}$ observed in the IR spectrum, led to the assumption that 1 was an olean-12-ene-type triterpene with two hydroxymethylene and two secondary hydroxyl groups and its molecular formula established as $\mathrm{C}_{30} \mathrm{H}_{50} \mathrm{O}_{4}$. The aforementioned data when compared with those of other known structurally related compounds suggested that $\mathbf{1}$ would have the same functionality on rings $\mathrm{A}$ and $\mathrm{B}$ as $3 \beta, 6 \beta, 23-$ trihydroxyolean-12-en-28-oic acid (5) previously isolated from Timonius timon (Rubiaceae). ${ }^{12}$ Indeed, the ${ }^{1} \mathrm{H}$ and ${ }^{13} \mathrm{C}$ NMR spectra of $\mathbf{1}$ showed close resemblance with those of $\mathbf{5}$, except for the signals due to the carboxylic group at C28 observed in the spectra of the latter, which were replaced by a singlet at $\delta_{\mathrm{H}} 4.06(2 \mathrm{H})$, indicative of a hydroxymethylene group at $\mathrm{C}-28$. Unambiguous assignments of the hydroxymethine carbons C-3 and C- 6 ( $\delta 73.4$ and 67.7, respectively) were established on the basis of connectivities observed from an HMBC experiment (Table 1). Accordingly, cross-peak correlations between the carbon signals of C-23 and C-24 and $\mathrm{H}-3$ resonance at
Table 1. ${ }^{1} \mathrm{H}(300 \mathrm{MHz})$ and ${ }^{13} \mathrm{C}(75 \mathrm{MHz}) \mathrm{NMR}$ spectral data of $3 \beta, 6 \beta$. 23,28-tetrahydroxyolean-12-ene (1) in Py- $d_{5}$ (TMS $\delta=0$ )

\begin{tabular}{|c|c|c|c|}
\hline $\mathrm{C} / \mathrm{H}$ & $\delta_{\mathrm{C}}$ & $\delta_{\mathrm{H}}$ & HMBC \\
\hline 1 & 41.2 & - & $\mathrm{H}-25\left({ }^{3} J_{\mathrm{CH}}\right)$ \\
\hline 2 & 28.4 & - & - \\
\hline 3 & 73.4 & $4.26 \mathrm{dd}(11.4,4.1)$ & $\mathrm{H}-23 \mathrm{~A}, \mathrm{H}-23 \mathrm{~B}\left({ }^{3} J_{\mathrm{CH}}\right)$ \\
\hline 4 & 44.1 & - & $\mathrm{H}-23, \quad \mathrm{H}-24\left({ }^{2} J_{\mathrm{CH}}\right)$ \\
\hline 5 & 49.4 & - & $\mathrm{H}-23, \mathrm{H}-25\left({ }^{3} J_{\mathrm{CH}}\right)$ \\
\hline 6 & 67.7 & 5.04 br s & - \\
\hline 7 & 41.2 & - & $\begin{array}{l}\text { H-6 }\left({ }^{2} J_{\mathrm{CH}}\right) ; \\
\text { H-26 }\left({ }^{3} J_{\mathrm{CH}}\right)\end{array}$ \\
\hline 8 & 39.3 & - & $\begin{array}{l}\text { H-26 }\left({ }^{2} J_{\mathrm{CH}}\right) ; \\
\text { H-6, H-27 }\left({ }^{3} J_{\mathrm{CH}}\right)\end{array}$ \\
\hline 9 & 48.8 & - & - \\
\hline 10 & 37.1 & - & $\begin{array}{l}\text { H-25 }\left({ }^{2} J_{\mathrm{CH}}\right) ; \\
\text { H-6 }\left({ }^{3} J_{\mathrm{CH}}\right)\end{array}$ \\
\hline 11 & 23.9 & - & $\mathrm{H}-12\left({ }^{2} J_{\mathrm{CH}}\right)$ \\
\hline 12 & 123.0 & $5.57 \mathrm{br} \mathrm{s}$ & $\mathrm{H}-18\left({ }^{3} J_{\mathrm{CH}}\right)$ \\
\hline 13 & 144.4 & - & $\mathrm{H}-18\left({ }^{3} J_{\mathrm{CH}}\right)$ \\
\hline 14 & 42.8 & - & $\begin{array}{l}\mathrm{H}-27\left({ }^{2} J_{\mathrm{CH}}\right) \\
\text { H-18, H-26 }\left({ }^{3} J_{\mathrm{CH}}\right)\end{array}$ \\
\hline 15 & 28.1 & - & - \\
\hline 16 & 24.0 & - & $\mathrm{H}-18\left({ }^{3} J_{\mathrm{CH}}\right)$ \\
\hline 17 & 46.8 & - & $\mathrm{H}-18\left({ }^{2} J_{\mathrm{CH}}\right)$ \\
\hline 18 & 42.2 & $3.33 \mathrm{dd}(13.5,3.6)$ & - \\
\hline 19 & 46.6 & - & $\mathrm{H}-29, \mathrm{H}-30\left({ }^{3} J_{\mathrm{CH}}\right)$ \\
\hline 20 & 31.0 & - & $\mathrm{H}-29, \mathrm{H}-30\left({ }^{2} J_{\mathrm{CH}}\right)$ \\
\hline 21 & 34.3 & - & H-29, H-30 $\left({ }^{3} J_{\mathrm{CH}}\right)$ \\
\hline 22 & 33.4 & - & - \\
\hline 23 & 67.2 & $\begin{array}{l}4.03 \mathrm{~d}(10.5) \\
4.38 \mathrm{~d}(10.5)\end{array}$ & $\mathrm{H}-3\left({ }^{3} J_{\mathrm{CH}}\right)$ \\
\hline 24 & 14.8 & $1.71 \mathrm{~s}$ & $\mathrm{H}-3\left({ }^{3} J_{\mathrm{CH}}\right)$ \\
\hline 25 & 17.6 & $1.65 \mathrm{~s}$ & - \\
\hline 26 & 18.7 & $1.60 \mathrm{~s}$ & - \\
\hline 27 & 26.3 & $1.24 \mathrm{~s}$ & - \\
\hline 28 & 64.5 & $406 \mathrm{~s}$ & - \\
\hline 29 & 23.9 & $0.98 \mathrm{~s}$ & H-30 $\left({ }^{3} J_{\mathrm{CH}}\right)$ \\
\hline 30 & 33.4 & $0.91 \mathrm{~s}$ & - \\
\hline
\end{tabular}

Coupling constants $(J$ in $\mathrm{Hz})$ are given in parentheses.

$\delta 4.26$, which in turn displayed one-bond ${ }^{1} \mathrm{H}^{-13} \mathrm{C}$ connectivity with the carbon signal at $\delta 73.4$ allowed the assignments of C-3/H-3. In a similar fashion, H-6 $(\delta 5.04)$ presented long-range correlations with C-7, C-8 and C-10. The appearance of $\mathrm{H}-6$ as a broad singlet in the ${ }^{1} \mathrm{H}$ NMR spectrum indicated its $\alpha$-equatorial orientation. A similar feature was also observed for the signal of H-6 in sumaresinolic acid methyl ester $\mathbf{2 a}\left[\delta_{\mathrm{H}} 4.53\right.$ (br s) $]$ and in $6 \beta$-hydroxymaslinic acid $\left[\delta_{\mathrm{H}} 4.85(\mathrm{~s})\right]^{13}$ which bear the same stereochemistry as H-6 in $\mathbf{1}$ and $\mathbf{5}$. The $\beta$-hydroxyl substitution at C-3 was inferred by the chemical shift and multiplicity of the axial $\mathrm{H}-3$ observed as a double doublet at $\delta 4.26(J 11.4$ and $4.1 \mathrm{~Hz})$. Thus, compound 1 was characterized as $3 \beta, 6 \beta, 23,28$-tetrahydroxyolean-12-ene. Further evidence for the structure of $\mathbf{1}$ was provided by additional two- and three-bond correlations discernible in the HMBC spectrum (Table 1). After acquisition of its 
spectroscopic data and storage at room temperature, however, compound $\mathbf{1}$ was decomposed to a mixture of oxidation products, as revealed by TLC and IR spectroscopy. This fact prevented further analysis of $\mathbf{1}$ by ESIMS.

After a series of column chromatography separations on silica gel of the hexane and $\mathrm{CHCl}_{3}$ solubles, obtained from partition of the ethanol extract from the trunk bark, seven triterpenes were isolated, together with stigmastane$3 \beta$-6 $\alpha$-diol (7), $\beta$-sitosterol, (-) catechin, $\beta$-D-tagatose ${ }^{14}$ and $\alpha$ - and $\beta$-D-fructose. ${ }^{14}$ The structures of these triterpenes have been established as friedelin, ${ }^{9}$ lupenone, ${ }^{9}$ lupeol, ${ }^{9}$ betulone, ${ }^{15}$ betulin, ${ }^{9}$ betulinic acid ${ }^{9}$ and taraxerol,,${ }^{9,16}$ on the basis of spectral analyses and by comparison with previously reported data. In spite of the wide distribution of these compounds in other plant genera, only few records are available for the presence of friedelan- and lupanetype triterpenoids in Terminalia, which is well known for the occurrence of triterpenes with oleanane and ursane skeletons. ${ }^{89}$ On the other hand, no records related to the isolation of taraxarane-type triterpenes, e.g. taraxerol, have hitherto been reported in this genus.

Compound 6 was identified by means of ${ }^{1} \mathrm{H}$ and ${ }^{13} \mathrm{C}$ NMR as arjunglucoside I, a triterpene glucoside previously characterized in several species of Terminalia (e.g., T. arjuna $^{17}$ and $T$. bellerica ${ }^{18}$ ).

The structure of 7 was shown to be of stigmastane- $3 \beta$ $6 \alpha$-diol on the basis of its ${ }^{1} \mathrm{H}$ and ${ }^{13} \mathrm{C}$ NMR spectral data, which were in accordance with those reported for the same steroid previously isolated from Trichosantes kirilowii (Cucurbitaceae), ${ }^{19}$ Spatholobus suberetus (Leguminosae) ${ }^{20}$ and Urtica dioica (Urticaceae) ${ }^{21}$ and until now, not yet described in Combretaceae.
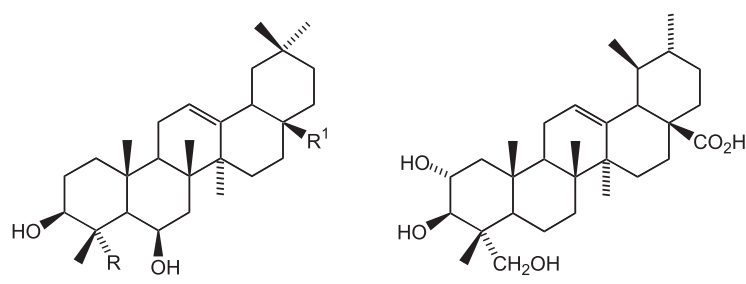

$1 \mathrm{R}, \mathrm{R}^{1}=\mathrm{CH}_{2} \mathrm{OH}$

$2 \mathrm{R}=\mathrm{CH}_{3}, \mathrm{R}^{\mathrm{I}}=\mathrm{CO}_{2} \mathrm{H}$

2a $\mathrm{R}=\mathrm{CH}_{3}, \mathrm{R}^{1}=\mathrm{CO}_{2} \mathrm{Me}$

$5 \mathrm{R}=\mathrm{CH}_{2} \mathrm{OH}, \mathrm{R}^{1}=\mathrm{CO}_{2} \mathrm{H}$
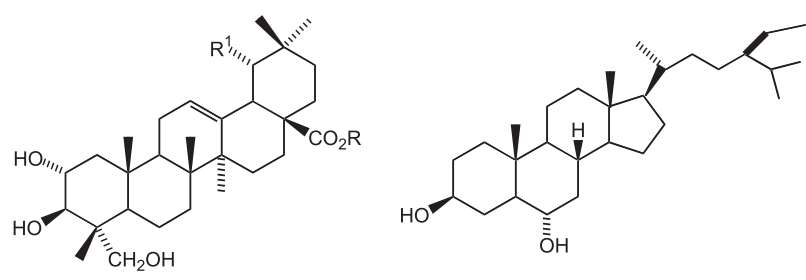

$4 \mathrm{R}, \mathrm{R}^{1}=\mathrm{H}$

$6 \mathrm{R}=\beta-\mathrm{D}-\mathrm{Glu}, \mathrm{R}^{1}=\mathrm{OH}$ $\beta$-sitosterol, sitosterol-3-O- $\beta$-D-glucopyranoside and (-) catechin were identified by comparison with authentic samples.

\section{Experimental}

\section{General experimental procedures}

${ }^{1} \mathrm{H}$ and ${ }^{13} \mathrm{C},{ }^{1} \mathrm{H}-{ }^{1} \mathrm{H}$ COSY, HMQC and HMBC NMR spectra were recorded on a Bruker DPX-300 spectrometer. Standard pulse sequences were used for homo- and heteronuclear correlation experiments. FT-IR spectra were obtained on $\mathrm{KBr}$ pellets in a Bomem MB-100 spectrometer. Optical rotations were measured with a Perkin-Elmer 341 polarimeter. GC analysis of the $n$-alkanes was performed on a Shimadzu QP-5000 GC, using a capillary column (LM-5, 30m x $0.25 \mathrm{~mm}$ ), FID, He as carrier gas, a temperature program from $80^{\circ}$ to $300{ }^{\circ} \mathrm{C}$ at $5^{\circ} \mathrm{min}^{-1}$ and Sigma $n$ alkane standards. Silica gel 60 70-230 and 230-400 mesh, RP-18 silica gel 230-400 mesh and Sephadex LH-20 were used for column chromatography. Preparative TLC was performed on silica gel $60 \mathrm{PF}_{254}$ plates.

\section{Plant material}

The leaves and trunk bark of Terminalia glabrescens Mart. were collected in Campo Grande, Mato Grosso do Sul, Brazil, in June, 1996. The plant was identified by Dr. Nilda Marquette (Jardim Botânico do Rio de Janeiro, RJ, Brazil) and a voucher specimen, 11264, is deposited in the Herbarium of the Universidade Federal de Mato Grosso do Sul.

\section{Extraction and isolation of chemical constituents}

Air-dried and powdered leaves $(1.9 \mathrm{~kg})$ were extracted at room temperature with $\mathrm{EtOH}$. The residue obtained from the EtOH extract was subsequently partitioned between EtOH- $\mathrm{H}_{2} \mathrm{O}$ (9:1) and hexane and $\mathrm{EtOH}-\mathrm{H}_{2} \mathrm{O}(1: 1)$ and $\mathrm{CHCl}_{3}$. The hexane phase $(11.9 \mathrm{~g})$ was subjected to $\mathrm{CC}$ on silica gel (70-230 mesh), eluted with a gradient of hexane$\mathrm{CHCl}_{3}$-EtOAc-MeOH resulting in 43 frs. of $125 \mathrm{~mL}$ each. Fraction 1 consisted of a mixture $\left(38 \mathrm{mg}\right.$ ) of $\mathrm{C}_{18}-\mathrm{C}_{33} n$ alkanes, while fraction 2 yielded squalene (48 $\mathrm{mg})$.

Fractions 16-17 afforded ursolic acid (10 mg) and a mixture $(5 \mathrm{mg})$ of ursolic and oleanolic acids. Further amounts of the former (15 mg) were obtained from fr. 19.

Fractions 20 and 33-39 yielded, respectively, a mixture of $2 \alpha$-hydroxyursolic and maslinic acids $(5 \mathrm{mg}$ ) and sitosterol-3-O- $\beta$-D-glucopyranoside ( $5 \mathrm{mg}$ ).

The $\mathrm{CHCl}_{3}$ phase (16.8 g) upon $\mathrm{CC}$ over silica gel (70- 
230 mesh) eluted with a gradient of hexane- $\mathrm{CHCl}_{3}$-EtOAc$\mathrm{MeOH}$ afforded 37 fractions of $125 \mathrm{~mL}$ each. Fractions 57 and 21-22 consisted of phytol (23 mg) and ursolic acid (43 mg), respectively.

Fraction 25 was separated by $\mathrm{CC}$ on RP-18 silica gel, eluting with $\mathrm{CHCl}_{3}-\mathrm{MeOH}-\mathrm{H}_{2} \mathrm{O}$ (2.0:4.0:1.5 to pure $\mathrm{MeOH}$ ) to yield 11 main fractions $\mathrm{A} \rightarrow \mathrm{K}$ (20 mL each). $\mathrm{CC}$ on silica gel (230-400 mesh) of fraction C eluted with $\mathrm{CHCl}_{3}$ $\mathrm{MeOH}$ (12.0:0.5) yielded further 29 fractions (10 mL each). From these, fractions $26-27$ consisted of a mixture of $2 \alpha$ hydroxyursolic acid, maslinic acid and $\mathbf{2}$ and was treated with an ethereal solution of diazomethane to give, after prep. TLC on silica gel [hexane- $\mathrm{CHCl}_{3}-\mathrm{MeOH}$ (3:6:1)], $2 \alpha$-hydroxyursolic acid methyl ester ( $7 \mathrm{mg}$ ) and a mixture $(19 \mathrm{mg}$ ) of methyl esters of sumaresinolic $\mathbf{2 a}$ and maslinic acids.

Prep TLC on silica gel [ $\mathrm{CHCl}_{3}$-isopropanol (12:2)] of fraction 28 yielded $\mathbf{1}$ (10 $\mathrm{mg})$.

Fraction 31 was further separated on a RP-18 silica gel (230-400 mesh) using $\mathrm{CHCl}_{3}-\mathrm{MeOH}_{2} \mathrm{H}_{2} \mathrm{O}$ (2.0:4.0:1.5 to pure $\mathrm{MeOH})$ as eluent to give 5 main fractions $(\mathrm{A} \rightarrow \mathrm{E})$. Fraction $\mathrm{B}$, after treatment with $\mathrm{Et}_{2} \mathrm{O} / \mathrm{CH}_{2} \mathrm{~N}_{2}$ followed by prep. TLC on silica gel [ $\left.\mathrm{CHCl}_{3}-\mathrm{MeOH}(10.0: 0.5)\right]$ gave $2 \mathbf{a}$ $(19 \mathrm{mg})$ and a mixture of methyl esters of $\mathbf{3}$ and $\mathbf{4}(40 \mathrm{mg})$. The same methylation and separation procedures applied to fr. $\mathrm{C}$ yielded 2- $\alpha$-hydroxyursolic acid methyl ester $(18 \mathrm{mg})$ and further amounts of a mixture of methyl esters of 3 and $4(10 \mathrm{mg})$. Fractions D and E consisted of 2- $\alpha$ hydroxyursolic acid (36 mg) and sitosterol-3-O- $\beta$-Dglucopyranoside (20 mg), respectively.

Air-dried and powdered trunk bark (1 kg) was extracted with $\mathrm{EtOH}$ at room temperature to obtain an $\mathrm{EtOH}$ extract which, after concentration under reduced pressure, was partitioned successively between $\mathrm{MeOH}-\mathrm{H}_{2} \mathrm{O}$ (9:1) and hexane and between $\mathrm{MeOH}-\mathrm{H}_{2} \mathrm{O}(1: 1)$ and $\mathrm{CHCl}_{3}$.

The hexane phase (4.5 g) was chromatographed on a silica gel (70-230 mesh) column eluted with increasing amounts of EtOAc in hexane to obtain 35 fractions of $100 \mathrm{~mL}$ each.

Fractions 5 and 6 afforded, respectively, friedelin $(15 \mathrm{mg})$ and a mixture of friedelin and lupenone $(20 \mathrm{mg})$.

Fraction 7 was treated with hot benzene. The insoluble residue was then washed with acetone to yield a precipitate and a supernatant fraction. The former was further chromatographed on a silica gel (230-400 mesh) column, with a gradient of hexane-EtOAc to give friedelin (25 mg) and taraxerol $(29 \mathrm{mg})$. In a similar fashion, the acetonesoluble fraction afforded lupeol (10 mg) and 7 ( $8 \mathrm{mg})$.

From fraction 11 was obtained $\beta$-sitosterol ( $15 \mathrm{mg}$ ).

The $\mathrm{CHCl}_{3}$ phase $(18.0 \mathrm{~g})$ was fractionated by $\mathrm{CC}$ on silica gel (70-230 mesh) eluted with a gradient of hexane-
EtOAc-MeOH leading to 76 fractions (125 mL each). Fractions 10-11, 12-16, 17 and 58-59 yielded betulone $(13 \mathrm{mg})$, betulin $(10 \mathrm{mg})$ betulinic acid (12 mg) and (-) catechin $(10 \mathrm{mg})$, respectively. Fractions 69 and 71 gave, respectively, 6 (18 $\mathrm{mg}$ ) and an unresolved mixture (16 mg) of $\beta$-D-tagatose and $\alpha$ - and $\beta$-D-fructose.

3 $\beta, 6 \beta, 23,28$-tetrahydroxyolean-12-ene (1). Colorless amorphous solid. $[\alpha]_{\mathrm{D}}^{23}:+29.9^{\circ}(\mathrm{MeOH} ; c 0.43)$. IR $\nu_{\max } / \mathrm{cm}^{-1}$ : 3429, 2940, 1457, 1035 (KBr). ${ }^{1} \mathrm{H}$ and ${ }^{13} \mathrm{C}$ NMR (Table 1).

Stigmastane-3 $\beta, 6 \alpha$-diol (7). ${ }^{1} \mathrm{H}$ NMR $(300 \mathrm{MHz}$, $\mathrm{CDCl}_{3}$ ): $\delta 3.56(\mathrm{tt}, J 11.0 ; 4.5 \mathrm{~Hz}, \mathrm{H}-3), 3.40$ (dt, $J 4.5 ; 10.7$ $\mathrm{Hz}$; H-6), 0.63 (s, $\mathrm{CH}_{3}-18$ ), 0.79 (s, $\mathrm{CH}_{3}-19$ ), 0.88 (d, J 6.4 $\left.\mathrm{Hz}, \mathrm{CH}_{3}-21\right), 0.81$ (d, J $\left.6.6 \mathrm{~Hz}, \mathrm{CH}_{3}-26\right), 0.81$ (d, J $6.6 \mathrm{~Hz}$, $\left.\mathrm{CH}_{3}-27\right), 0.80$ (t, J 7.8 Hz, $\left.\mathrm{CH}_{3}-29\right) .{ }^{13} \mathrm{C} \mathrm{NMR}(75 \mathrm{MHz}$, $\left.\mathrm{CDCl}_{3}\right): \delta 37.2(\mathrm{C}-1), 31.0(\mathrm{C}-2), 71.3(\mathrm{C}-3), 32.2(\mathrm{C}-4)$, 51.7 (C-5), 69.5 (C-6), 41.7 (C-7), 34.3 (C-8), 53.8 (C-9), 36.3 (C-10), 21.1 (C-11), 39.8 (C-12), 42.6 (C-13), 56.2 (C-14), 24.2 (C-15), 28.2 (C-16), 56.1 (C-17), 12.0 (C-18), 13.4 (C-19), 36.1 (C-20), 18.7 (C-21), 33.9 (C-22), 26.0 (C-23), 45.8 (C-24), 29.1 (C-25), 19.8 (C-26), 19.0 (C-27), 23.0 (C-28), 12.0 (C-29).

\section{Acknowledgements}

The authors are grateful to CPq-PROPP-UFMS and PROAP-CAPES for financial support and to CNPq for the award of fellowships. Thanks are also due to Dr. Nilva R. Poppi and Luiz Leonardo S. Viana (Departamento de Química, UFMS) for GC analysis of the $n$-alkanes.

\section{References}

1. Nandy, A. K.; Chakraborty, A.; Podder, G.; Fitoterapia 1997, LXVIII, 178

2. Sato, Y.; Oketani, H.; Singyouchi, K.; Ohtsubo, T.; Masaru, K.; Shibata, H.; Higuti, T.; Biol. Pharm. Bull. 1997, 20, 401.

3. Valsaraj, R.; Pushpangadan, P.; Smitt, U. K.; Adsersen, A.; Christensen, S. B.; Sittie, A.; Nyman, U.; Nielsen, C.; Olsen, C. E .; J. Nat. Prod. 1997, 60, 739

4. Pettit, G.R, Hoard, M. S.; Doubek, D. L.; Schmidt, J. M.; Pettit, R. K.; Tackett, L. P.; Chapuis, J.; J. Ethnopharmacol. 1996, 53, 57.

5. Kandil, F. E.; Soliman, A. M.; Skodack, S. R.; Mabry, T. J.; Asian J. Chem. 1999, 11, 1001.

6. Lin, C. C.; Hsu, Y. F.; Lin, T. C.; Hsu, F. L.; Hsu, H. Y.; J. Pharm. Pharmacol. 1998, 50, 789.

7. Anand, K. K.; Singh, B.; Saxena, A. K.; Chandan, B. K.; Gupta, V. N.; Bhardwaj, V.; Pharmacol. Res. 1997, 36, 315.

8. Mallavarapu, G. R. In Studies in Natural Products Chemistry; Rahman, A., ed.; Elsevier Science Publ.: Amsterdam, 1990, vol. 7, p 131. 
9. Ahmad, U. V.; Rahman, A.; Handbook of Natural Products Data. Volume 2. Pentacyclic Triterpenoids; Elsevier: Amsterdam, 1994.

10. Pouchert, C. J.; Behnke, J.; The Aldrich Library of ${ }^{13} \mathrm{C}$ and ${ }^{1} \mathrm{H}$ FTNMR Spectra, $1^{\text {st }}$ ed., Aldrich Chemical Company, Inc: Milwaukee, 1993, vol.1.

11. Mahato, S. B.; Kundu, A. P.; Phytochemistry 1994, 37, 1517.

12. Khan, I. A.; Sticher, O.; J. Nat. Prod. 1993, 56, 2163.

13. Zucaro Z.,Y. L.; Compagnone R. S.; Hess, S. C.; Delle Monache, F.; J. Braz. Chem. Soc. 2000, 11, 241.

14. Breitmaier, E.; Voelter, W.; Carbon-13 NMR Spectroscopy: High Resolution Methods and Application in Organic Chemistry and Biochemistry, $3^{\text {rd }}$. rev. ed.; VCH: Weinheim, 1989.

15. Cole, B. J. W.; Bentley, M. D.; Hua, Y.; Hölzforschung 1991, 45,265 .
16. McLean, S.; Reynolds, W. F.; Yang, J.; Jacobs, H.; Jean-Pierre, L. L.; Magn. Reson. Chem. 1994, 32, 422.

17. Honda, T.; Murae, T.; Tsuyuki, T.; Takahashi, T.; Sawai, M.; Bull. Soc. Chem. Jpn. 1976, 49, 3213.

18. Nandy, A. K.; Podder, G.; Sahu, N. P.; Mahato, S. B.; Phytochemistry 1989, 28, 2769.

19. Kimura, Y.; Akihisa, T.; Yasukawa, K.; Takido, M.; Tamura, T.; Chem. Pharm. Bull. 1995, 43, 1813.

20. Fukuyama, Y.; Nakano, Y.; Pei-Wu, G.; Rui, W.; Sumitomo, J.; Jinxian, B.; Nakagawa, K.; Planta Med. 1988, 54, 34.

21. Chaurasia, N.; Wichtl, M.; J. Nat. Prod. 1987, 50, 881.

Received: September 24, 2002 Published on the web: April 11, 2003 